\title{
COVID-19 survivors with Post Intensive Care Syndrome: Key rehabilitation strategies for Africa
}

\author{
Chukwuebuka Okeke ${ }^{1}$, Michael Kalu², and Rita Ativie $^{3}$ \\ ${ }^{1}$ Nnamdi Azikiwe University \\ ${ }^{2}$ McMaster University Faculty of Health Sciences \\ ${ }^{3}$ University of Nigeria
}

October 30, 2020

\begin{abstract}
The emergence of coronavirus diseases (COVID-19) has presented a global health threat. The number of COVID-19 cases continues to increase in Africa; this poses a challenge to the African healthcare system, particularly the intensive care unit (ICU). More so, individuals with severe COVID-19 would often have a prolonged intensive care stay, requiring mechanical ventilation and sedation and this may increase their risk of developing physical, cognitive and psychosocial impairments. These post-ICU sequelae of morbidities have been termed Post Intensive Care Syndrome. The African healthcare system needs to be prepared to manage the adverse effects of Post Intensive Care Syndrome (PICS) largely characterized by a decline in functional capacity and health-related quality of life. It is thus expedient that multi-targeted measures such as early rehabilitation, adequate screening, patient/caregiver education and post-discharge rehabilitation be adopted to combat imminent poor health outcomes in COVID-19 survivors. In this editorial, we provided a brief review of PICS and highlighted strategies for preventing and managing PICS in the critically ill within the African context Key words: Pandemic, COVID-19 Survivors, African healthcare, Intensive Care Unit, Rehabilitation
\end{abstract}

Title: COVID-19 survivors with Post Intensive Care Syndrome: Key rehabilitation strategies for Africa

\section{Abstract}

The emergence of coronavirus diseases (COVID-19) has presented a global health threat. The number of COVID-19 cases continues to increase in Africa; this poses a challenge to the African healthcare system, particularly the intensive care unit (ICU). More so, individuals with severe COVID-19 would often have a prolonged intensive care stay, requiring mechanical ventilation and sedation and this may increase their risk of developing physical, cognitive and psychosocial impairments. These post-ICU sequelae of morbidities have been termed Post Intensive Care Syndrome. The African healthcare system needs to be prepared to manage the adverse effects of Post Intensive Care Syndrome (PICS) largely characterized by a decline in functional capacity and health-related quality of life. It is thus expedient that multi-targeted measures such as early rehabilitation, adequate screening, patient/caregiver education and post-discharge rehabilitation be adopted to combat imminent poor health outcomes in COVID-19 survivors. In this editorial, we provided a brief review of PICS and highlighted strategies for preventing and managing PICS in the critically ill within the African context

Key words: Pandemic, COVID-19 Survivors, African healthcare, Intensive Care Unit, Rehabilitation

Introduction 
Coronavirus disease (COVID-19) is a highly contagious disease caused by SARS-CoV-2. It primarily affects the respiratory system with possible complications such as acute respiratory disease syndrome (ARDS), multiple organ dysfunctions, and sepsis ${ }^{1}$. Other commonly reported symptoms include cough, low grade fever, fatigue, shortness of breath, chest pain, headaches, neurocognitive difficulties, thromboembolic conditions, depression and other mental health conditions ${ }^{2,3}$. Although knowledge of the course and symptom manifestation of the disease is still evolving and trials are ongoing ${ }^{4,5}$, of concern is that individuals severely affected by COVID-19 disease could require intensive care and may rely on mechanical ventilator support for a considerably extended period ${ }^{2,6,7}$.

Typically, survivors of critical illness are often faced with persistent and potentially long-lasting problems, including a decline in physical function, poor mental health and reduced cognition ${ }^{8,9}$. This constellation of new or worsening physical, cognitive and psychosocial impairments in critical illness survivors has been described as Post Intensive Care Syndrome (PICS) ${ }^{10}$. Intensive care requirement and disease nature of COVID-19 suggests that survivors are a high risk group for PICS $^{6}$.

The first case of COVID-19 in Africa was confirmed in Egypt on the14th of February 2020. Since then, the numbers of COVID-19 cases have continued to increase with a higher incidence in countries like South Africa, Nigeria and Algeria ${ }^{11}$. With this increase in COVID-19 cases in Africa, prolonged stay in the Intensive Care Unit (ICU) among individuals with severe COVID-19 infection is inevitable. As such, there is need to create awareness for clinicians, especially in developing regions like Africa while making explicit rehabilitation recommendations for the trajectory of care for critically ill COVID-19 patients ${ }^{12}$. This is envisaged to help in optimizing their survivorship experience.

In this editorial, we provided a brief overview of the clinical features of PICS, and highlighted the strategies that the clinicians could adopt in managing COVID-19 patients with PICS.

\section{Post Intensive Care Syndrome (PICS) and its clinical features}

Post intensive care syndrome (PICS) is a constellation of new or worsening impairments in physical, mental, or cognitive abilities in critical illness survivors who have received intensive care ${ }^{10,13}$. Clinical features of the elements of PICS are cognitive, mental health and physical impairment. While PICS affects mostly the survivor, it can also affect the family member of the survivor, especially their mental health ${ }^{13}$.

According to Harvey and Davidson ${ }^{13}$, although not among COVID-19 survivors, the symptoms of mental (e.g. anxiety) and cognitive impairment occurred in $23-48 \%$ and $30-80 \%$ of critical illness survivors with PICS in a developed country. Similarly, physical consequences, including ICU-acquired weakness, occur in $25-80 \%$ of individuals on mechanical ventilation for more than four days ${ }^{13}$.

Cognitive impairment resulting from PICS affects the executive function, memory, attention, visuo-spatial and processing speed, and this could persist months to years after discharge from critical care ${ }^{14}$. Cognitive impairment negatively impacts independent functioning such as driving and managing complex medication resulting in reduced quality of life ${ }^{14}$. Individuals with delirium ${ }^{14}$ and pre-existing cognitive deficits could be at a higher risk of PICS-related cognitive impairments ${ }^{15}$.

Examples of mental health impairment include anxiety, acute stress disorders, post-traumatic stress disorder, and depression. These symptoms co-occur in critical illness survivors ${ }^{16}$. Unfortunately, the nature of COVI19 disease which entails that patients are isolated limits the presence of family members and could further worsen mental health outcomes. The impact of poor mental health and persistent delusional memories could be functionally debilitating ${ }^{8}$.

Physical impairment affects pulmonary, neuromuscular and physical functioning. Ohtake et $\mathrm{al}^{9}$ in a systematic review of 15 studies, used the International Classification of Functioning, Disability and Health (ICF) framework to identify the impairment of body functions and structures, activity limitations, and participation restrictions associated with PICS. See table 1

\section{Strategies for managing COVID-19 patients with PICS}


Effective and efficient rehabilitation care is needed to manage COVID-19 survivors with PICS. We propose strategies, based on available evidence, which could be adopted by critical care clinicians in the rehabilitation care of COVID-19 patients with PICS. These considerations stem from data from developed countries and indirect evidence from knowledge of critical care rehabilitation; and we suggest they are adapted to suit the peculiarity of the African healthcare system. These considerations are not mutually exclusive, and its practice is iterative [i.e. a lot of clinical discussion with the multidisciplinary members] across the continuum of care.

Rehabilitation care for COVID-19 patients with PICS admitted in the ICU should include early ICU rehabilitation upon admission, screening on discharge, and discharging into a post rehabilitation program such as primary healthcare centers or rehabilitation homes. Patient/family education, efficient and effective communication between healthcare workers - discharger and the receiver, patients/family should be a continuous process throughout the continuum of care (See Figure 1).

\section{Early ICU Rehabilitation}

Early progressive mobility in critically ill patients is safe and feasible and is shown to reduce functional decline, improve physical performance and cognitive function, and optimize the quality of life in critical illness survivors ${ }^{24,25}$. A review by Stiller ${ }^{26}$ provides evidence on the efficacy of early rehabilitation (ER) on secondary outcomes such as ICU and hospital length of stay. Findings from previous studies have also shown short-term improvements in physical-related outcomes such as muscle strength and a reduction in the incidence of ICU-acquired weakness ${ }^{27,}{ }^{28}$. Delirium, a significant cause of cognitive impairment, is also effectively combated using early mobility ${ }^{19}$.

Unfortunately, several patient-, clinician- and institutional related barriers have been identified to challenge the implementation of ER for critically ill patients across different ICUs in Africa ${ }^{29,30,31}$. Notable amongst the "modifiable" barriers includes; lack of expertise on ER amongst acute care clinicians ${ }^{30}$, staff unavailability ${ }^{29}$, lack of rehabilitation equipments ${ }^{31}$ and excessive sedation practice ${ }^{29,31}$. Low utilization of rehabilitation services in Africa ${ }^{32}$, possibly resulting from these and many other barriers, has been corroborated by anecdotal reports during this pandemic ${ }^{33}$.

This is thus a call to action for critical care centers across Africa to adopt multi-targeted strategies to (1) address these identified barriers, (2) facilitate the implementation of ER and (3) maintain an ICU culture of prioritizing ER. Interestingly, in the case of this present pandemic, there exist international ${ }^{34}$ as well as local guidelines $^{35}$ to ensure safety and efficiency in the acute rehabilitation of individuals with severe COVID-19.

\section{Screening}

Every patient who has received intensive care should be screened for PICS on discharge and during followups $^{36}$. Screening should be performed by a multidisciplinary team consisting of a critical care physician, a physical therapist, an occupational therapist, psychologist, and other inter-professional team members involved in planning care for ICU survivors and their families/caregivers ${ }^{37}$. Performance-based and patientreported outcome measuring instruments are available to assist in the early detection of PICS such as Repeatable Battery for the Assessment of Neuropsychological Status, Short Physical Performance Battery and WHO Disability Assessment Schedule. ${ }^{38}$ Furthermore, owing to the nature of COVID-19 and the need to limit disease transmission, screening can be done virtually ${ }^{35,39}$.

\section{Post-Discharge rehabilitation}

Immediate and individually tailored post-acute ICU rehabilitation efforts should be targeted towards ameliorating problems across all three PICS domains (physical, mental and cognitive) based on findings from personalized evaluation. Specialist referral should be sought if need be. ${ }^{40}$ Cognitive rehabilitation ${ }^{41}$ and the use of ICU diaries ${ }^{42}$ are useful in managing PICS-related cognitive symptoms, thus improving psychosocial well-being. Post ICU rehabilitation also helps to improve critical illness-related depressive symptoms and mental health-related quality of life ${ }^{43}$. A recent report has also shown cardio-pulmonary rehabilitation for COVID 19 survivors to be safe and effective ${ }^{44}$. Tele-consultations using telephone, a seemingly feasible 
tele-health option in Africa ${ }^{45}$, is also an efficient and feasible alternative in providing psychosocial support to patients, family members and caregivers after their ICU stay ${ }^{46}$.

Although evidence for the efficacy of post ICU rehabilitation is rather inconclusive ${ }^{47}$, practice guidelines recommend its implementation considering the complexity of critical illness presentations and the need to optimize patient outcomes and improve survivorship ${ }^{35,39,48}$. Considering the peculiarity of the healthcare systems in Africa, different countries have put up guidelines to incorporate key considerations for rehabilitating COVID-19 patients in African settings ${ }^{35}$. There is hence a need for close collaboration amongst rehabilitation specialists, community health service providers and other multi-professional teams with experience in providing rehabilitation interventions for mental, cognitive and physical sequelae of critical illness.

\section{Education: Patient, Family and Care-giver}

Families and caregivers of critical illness survivors also feel the impact of the disease burden ${ }^{44}$. Education of patients, family members and caregivers should be continuous across the care, on admission, during discharge and on follow-ups ${ }^{49}$. However, education should be aligned with the stage of care. For instance, family members of individuals with COVID-19 who are admitted into the hospital should be informed about the possibility of their family member developing PICS or other associated syndromes. On discharge, survivors and their families could be provided with educational materials such as brochures and informative websites as part of their discharge packages ${ }^{40}$. Adequate education of these family members would improve their proficiency in "care-giving" post discharge.

\section{Suggested post-discharge rehabilitation locations}

On discharge from acute care, coordinated rehabilitation care for COVID-19 survivors with PICS should continue at primary health care centers, rehabilitation homes, or home-based rehabilitation ${ }^{40}$. It is thus paramount that healthcare professionals working in these outfits are trained to identify ICU-related morbidities and make informed decisions on care ${ }^{50}$. As disease transmission remains a concern, rehabilitation professionals should also be trained on the use of safety equipment and infection control practices to ensure safe provision of care $^{51}$.

At the primary health care center, multidisciplinary efforts to recognize and ameliorate impairments in body functions and structures, activity limitations, and participation restrictions will improve patient outcomes and quality of life for people who have received intensive care ${ }^{9}$. Thus, COVID-19 survivors would arguably benefit from such care. As most primary healthcare centers in Africa may have limited rehabilitation professionals $^{52}$, we advocate that survivors be also discharged to other facilities with rehabilitation professionals such as rehabilitation homes, home-based rehabilitation and rehabilitation in outpatient settings ${ }^{53}$. As such, efforts by concerned authorities in improving the functionality of government-owned rehabilitation outfits, which are relatively more affordable, are recommended. This will possibly reduce the healthcare burden on the ICUs in most African hospitals. Also, considering the need to limit the risk of infection transmission, rehabilitating survivors at home using tele-health approaches, becomes a viable alternative to traditional face to face rehabilitation ${ }^{51,54}$.

\section{Conclusion}

The increase in the COVID-19 cases calls for a rethinking of healthcare service delivery in Africa as survivors are at risk of long term morbidity resulting from the burden of critical illness. Based on the literature, we have provided possible rehabilitation care for COVID-19 survivors with PICS in Africa.

Author contributions: Okeke CO, Kalu M and Ativie RN contributed to conceptualizing, drafting, writing and critically reviewing all contents of this editorial

Acknowledgements: We wish to thank members of the Emerging Researchers \& Professionals in AgeingAfrican Network, Nigeria for their support in writing up this editorial.

Funding: None 


\section{Conflicts of interest: None}

Ethical Approval: Ethical approval was not required for this editorial

\section{References}

1. Gaythorpe K, Imai N, Cuomo-Dannenburg G et al. Imperial College London COVID-19 Response Team. Report 8: Symptom progression of COVID-19. https://doi.org/10.25561/77344. Accessed May 2020

2. Assaf G, Davis H, McCorkell L, et al. An analysis of the prolonged COVID-19 symptoms survey by Patient-Led Research Team. Patient Led Research, 2020. https://patientresearchcovid19.com/.

3. Dasgupta A, Kalhan A, Kalra S. Long term complications and rehabilitation of COVID-19 patients. J Pak Med Assoc 2020; 70:S131-5. doi: 10.5455/JPMA.32 pmid: 32515393

4. ClinicalTrials.gov. Long-term impact of infection with novel coronavirus (COVID-19) (LIINC). 2020. https://clinicaltrials.gov/ct2/show/record/NCT04362150

5. ISRCTN Registry. ISRCTN10980107: Long-term follow up of adults hospitalized with COVID-19. 2020. http://www.isrctn.com/ISRCTN10980107.

6. CDC COVID-19 Response Team. Severe Outcomes Among Patients with Coronavirus Disease 2019 (COVID-19) - United States, February 12-March 16, 2020. MMWR Morb Mortal Wkly Rep. 2020 Mar 27; 69: 343-346. doi: 10.15585/mmwr.mm6912e2. PMID: 32214079.

7. Rodriguez-Morales AJ, Cardona-Ospina JA, Gutiérrez-Ocampo E, Villamizar-Peña R, Holguin-Rivera Y, Escalera-Antezana JP, et al. Clinical, laboratory and imaging features of COVID-19: A systematic review and meta-analysis. Travel Med Infect Dis 2020; 34: 101623. doi: 10.1016/j.tmaid.2020.101623.

8. Hashem MD, Nallagangula A, Nalamalapu S, et al. Patient outcomes after critical illness: a systematic review of qualitative studies following hospital discharge. Crit Care 2016; 20: 345-355. http://doi.org/10.1186/s13054-016-1516-x

9. Ohtake PJ, Lee AC, Scott JC, Hinman RS et al. Physical Impairments Associated With Post-Intensive Care Syndrome: Systematic Review Based on the World Health Organization's International Classification of Functioning, Disability and Health Framework. Phys. Ther 2018; 98: 631- 645. DOI: $10.1093 / \mathrm{ptj} / \mathrm{pzy} 059$

10. Needham DM, Davidson J, Cohen H, et al. Improving long-term outcomes after discharge from intensive care unit: report from a stakeholders' conference. Crit Care Med 2012; 40: 502-509. https://doi.org/10.1097/ccm.0b013e318232da75

11. World Health Organization. Weekly bulletin on outbreaks and other emergencies. 2020. Available from: https://apps.who.int/iris/bitstream/handle/10665/331892/OEW17-2026042020.pdf. Accessed August 2020

12. Jaffri A, Jaffri UA. Post-Intensive care syndrome and COVID-19: crisis after a crisis? Heart Lung. 2020; 18:S0147-9563(20)30266-1. doi: 10.1016/j.hrtlng.2020.06.006. Epub ahead of print. PMID: 32690219; PMCID: PMC7301100

13. Harvey MA, Davidson JE. Post-intensive care syndrome: right care, right now... and later. Crit Care Med 2016; 44: 381-385.

14. Pandharipande PP, Girard TD, Jackson JC, et al. Long-term cognitive impairment after critical illness. N Engl J Med 2013; 369: 1306-1316.

15. Inoue S, Hatakeyama J, Kondo Y, Hifumi T, Sakuramoto H, Kawasaki T. Post intensive care syndrome: its pathophysiology, prevention, and future directions. Acute Med Surg 2019; 6: 233-246

16. Bievenu OJ, Colantuoni E, Mendez-Tellez PA, et al. Cooccurence of and remission from general anxiety, depression, and posttraumatic stress disorder symptoms after acute lung injury: a 2-year longitudinal study. Crit Care Med 2015; 43:642

17. Cabrera-Benitez NE, Laffey JG, Parotto M, et al. Mechanical ventilation-associated lung fibrosis in acute respiratory distress syndrome: a significant contributor to poor outcome. Anesthesiology 2014; 121: 189-198.

18. Tobin MJ, Laghi F, Jubran A. Narrative review: ventilator-induced respiratory muscle weakness. Ann Intern Med 2010; 153: 240-245. 
19. Kress JP, Hall JB. ICU-acquired weakness and recovery from critical illness. N Engl J Med 2014; 371: 287-288.

20. Pfoh ER, Wozniak AW, Colantuoni E, et al. Physical declines occurring after hospital discharge in ARDS survivors: a 5-year longitudinal study. Intensive Care Med 2016; 42: 1557-1566.

21. Hopkins RO, Suchyta MR, Kamdar BB, Darowski E, Jackson JC, Needham DM. Instrumental activities of daily living after critical illness: a systematic review. Ann Am Thorac Soc. 2017; 14: 1332- 1343.

22. Kamdar BB, Suri R, Suchyta MR, et al. Return to work after critical illness: a systematic review and meta-analysis. Thorax 2019;0 : 1-11. Doi:10.1136/thoraxjnl-2019-213803

23. Oeyen SG, Vandijck DM, Benoit DD, Annemans L, Decruyenaere JM. Quality of life after intensive care: a systematic review of the literature. Crit Care Med 2010; 38: 2386-2400.

24. Martínez-velilla N, Cadore EL, Casas-herrero A, Idoate-saralegui F, Izquierdo M. Physical activity and early rehabilitation in hospitalized elderly medical patients: systematic review of randomized clinical trials. J Nutr Health Aging 2016: 20: 738-751. https://doi.org/10.1007/s12603-016-0683-4

25. Fernández PA, Martin MR, Salgado JG, García DF. Rehabilitation and early mobilization in the critical patient: systematic review. J Phys Ther Sci 2018; 30: 1193-1201. https://dx.doi.org/10.1589\%2Fjpts.30.1193

26. Stiller, K. Physiotherapy in intensive care: an updated systematic review. Chest 2013; 144: 825-847. https://doi.org/10.1378/chest.12-2930

27. Fuke R, Hifumi T, Kondo Y, Hatakeyama J, Takei T, Yamakawa K, Inoue S, Nishida O. Early rehabilitation to prevent post-intensive care syndrome in patients with critical illness: a systematic review and meta-analysis. BMJ Open 2018; 8: e019998

28. Anekwe DE, Biswas S, Bussieres A, Spahija J. Early Rehabilitation Reduces the Likelihood of Developing Intensive Care Unit-Acquired Weakness: A systematic Review and Meta-Analysis. Physio 2019: $1-10$.

29. Plessis ID, Arnold N, Hayden M, Mashego M, Masoga R, Mkiva C. knowledge, barriers and facilitators of early mobilization of critically ill patients among nurses and physiotherapists. South African Journal of Critical Care 2019; 35 (1): 34

30. Akinremi AA, Ogwu S, Sanya AO, Sanusi AA, Osinaike B. Early mobilization in the ICU: A multicenter survey of clinicians' knowledge, attitude and practices in resource-limited hospital settings. Ann Med Health Sci Res 2020; 778-784

31. Tadyanemhandu C, Van Aswegen H, Ntsiea V. organizational structures and early mobilization practices in South African public sector intensive care units-A cross-sectional study. J Eval in Clin Pract 2020; 1-11.

32. Agho AO, John EB. Occupational therapy and physiotherapy education and workforce in Anglophone sub-Saharan African countries. Human Resources for Health 2017;15:37.

33. Abdullahi A, Bello B, Mukhtar NB, Kaka B, Abba MA, Usman JS, Shittu A, Mayana KI, Maiwada SA, Mohammed J. Physiotherapy management of COVID-19 in Africa: Ongoing efforts, challenges, and future directions. Physiother Theory Pract. 2020; 36:871-872.

34. Thomas P, Baldwin C, Bissett B, et al. Physiotherapy management for COVID-19 in the acute hospital setting. Recommendations to guide clinical practice. 2020. Version 1.0, published 23 March 2020. https://doi.org/10.1016/j.jphys.2020.03.011

35. Ngeh NE, Chigbo NN, Whitehouse Z et al. Rehabilitation of patients with COVID-19 in African Settings: Guidance for Community Based Rehabilitation Workers, Physiotherapists, Occupational Therapists, Speech and Language Therapists, and Assistants. May 24, 2020. https://www.wcptafrica.org/ and https://afri-can.org/

36. Colbenson GA, Johnson A, Wilson ME. Post-intensive care syndrome: impact, prevention, and management. Breathe 2019; 15: 98-101. https://dx.doi.org/10.1183\%2F20734735.0013-2019

37. Philips M, Turner-Stokes L, Wade D, Walton K. Rehabilitation in the wake of Covid19 - A Phoenix from the ashes. British Society of Rehabilitation Medicine 2020. https://www.bsrm.org.uk/downloads/covid-19bsrmissue1-published-27-4-2020.pdf. Accessed June 2020 
38. Spies CD, Krampe H, Paul N, et al. Instruments to measure outcomes of post-intensive care syndrome in outpatient care settings- Results of an expert consensus and feasibility field test. Journal of the Intensive Care Society 2020: 1-16. https://doi.org/10.1177\%2F1751143720923597

39. Simpson R, Robinson L. Rehabilitation after critical illness in people with COVID-19 infection. Am J Phys Med Rehabil 2020; 99: 470-474.

40. Greenhalgh T, Knight M, A'Court C, Buxton M, Husain L. Management of post-acute covid-19 in primary care. BMJ 2020; 370: m3026. http://dx.doi.org/10.1136/bmj.m3026

41. Jackson JC, Ely EW, Morey MC, et al. Cognitive and physical rehabilitation of intensive care unit survivors: results of the RETURN randomized controlled pilot investigation. Crit Care Med 2012; 40: 1088-1097. https://doi.org/10.1097/ccm.0b013e3182373115

42. Ullman AJ, Aitken LM, Rattray J, et al. Intensive care diaries to promote recovery for patients and families after critical illness: a Cochrane systematic review. Int J Nurs Stud 2015; 52: 1243-1253. https://doi.org/10.1016/j.ijnurstu.2015.03.020

43. Rosa RG, Ferreira GE, Viola TW, Robinson CC, Kochhann R, Berto PP, Biason L, Cardoso PR, Falavigna M, Teixeira C. Effects of post-ICU follow-up on subject outcomes: A systematic review and meta-analysis. J Crit Care 2019; 52:115-125. doi: 10.1016/j.jcrc.2019.04.014

44. Hermann M, Pekacka-Egli A, Witassek F, Baumgaertner R, Schoendorf S, Spielmanns M. Feasibility and Efficacy of Cardiopulmonary Rehabilitation After COVID-19. Am J Phys Med Rehabil 2020; 99: 865-869

45. Odole AC and Ojo OD. 'A telephone-based physiotherapy intervention for patients with osteoarthritis of the knee'. International Journal of Telerehabilitation 2013; 5: 11-20

46. Cox CE, Porter LS, Hough CL, et al. Development and preliminary evaluation of a telephone-based coping skills training intervention for survivors of acute lung injury and their informal caregivers. Intensive Care Med 2012; 38: 1289-1297. DOI: 10.1007/s00134-012-2567-3

47. Kiekens C. Follow-up services for improving long-term outcomes in intensive care unit (ICU) survivors - a cochrane review summary with commentary. J Rehabil Med 2019; 51: 879-882

48. Pan American Health Organisation. Rehabilitation considerations during the COVID-19 outbreak. https://iris.paho.org/handle/10665.2/52035. Accessed October 2020.

49. King J, O'Neill B, Ramsay P, et al. Identifying patients' support needs following critical illness: a scoping review of the qualitative literature. Crit Care2019; 23: 187

50. Sevin CM, Jackson JC. Post-ICU clinics should be staffed by ICU clinicians. Crit Care Med 2019; 47: 268-72. https://doi.org/10.1097/ccm.0000000000003535

51. Grabowski DC, Joynt Maddox KE. Post-acute care preparedness for COVID-19: Thinking ahead. JAMA 2020; 323: 2007-2008. DOI: 10.1001/ jama.2020.4686.

52. World Health Organization. Access to rehabilitation in primary health care: an ongoing challenge. World Health Organization. https://apps.who.int/iris/handle/10665/325522. 2018. License: CC BYNC-SA 3.0 IGO

53. Korupolu R, Francisco GE, Levin H, Needham DM. Rehabilitation of critically Ill COVID-19 survivors. J Int Soc Phys Rehabil Med 2020; 3:45-52. DOI: 10.4103/jisprm.jisprm_8_20

54. Salawu A, Green A, Crooks MG, Brixey N, Ross DH, Sivan M. A Proposal for Multidisciplinary TeleRehabilitation in the Assessment and Rehabilitation of COVID-19 Survivors. Int J Environ Res Public Health. 2020; 17: 4890. doi: 10.3390/ijerph17134890.

\section{Hosted file}

Table 1 (JECP).pdf available at https://authorea.com/users/371479/articles/489811-covid-19survivors-with-post-intensive-care-syndrome-key-rehabilitation-strategies-for-africa

\section{Hosted file}

Figure 1.pdf available at https://authorea.com/users/371479/articles/489811-covid-19survivors-with-post-intensive-care-syndrome-key-rehabilitation-strategies-for-africa 